\title{
A Reforma Psiquiátrica Brasileira como luta pelo reconhecimento e progresso moral
}

\author{
The Brazilian Psychiatric Reform as a struggle for recognition and \\ moral progress
}

Martín Mezza', Mônica de Oliveira Nunes de Torrenté1

DOI: $10.1590 / 0103-11042020 E 320$

RESUMO A partir de um trabalho de aproximação e reelaboração conceitual entre a teoria do reconhecimento e o paradigma da desinstitucionalização, buscou-se destacar os traços que permitam retratar a Reforma Psiquiátrica Brasileira (RPB) como luta pelo reconhecimento e progresso moral da sociedade. Com isso, além de contribuir com material empírico para as teses da teoria do reconhecimento e ampliar a normatividade do conceito de reconhecimento, pretende-se colaborar para o desenvolvimento teórico do processo de desinstitucionalização e para os esforços que visam reanimar as lutas do coletivo antimanicomial para transitar pelos impasses estruturais e conjunturais.

PALAVRAS-CHAVE Desinstitucionalização. Reconhecimento social. Desenvolvimento moral. Ética.

\begin{abstract}
Based on a work of approximation and conceptual re-elaboration between the theory of recognition and the paradigm of deinstitutionalization, we sought to highlight the features that make it possible to portray the Brazilian Psychiatric Reform as a struggle for the recognition and moral progress of society. Thus, in addition to contributing with empirical material for the recognition theory theses and expanding the normativity of the concept of recognition, is intended to collaborate for the theoretical development of the deinstitutionalization process and for the efforts aimed at reviving the struggles of the anti-asylum collective to transit through structural and conjunctural impasses.
\end{abstract}

KEYWORDS Deinstitutionalization. Social desirability. Développement moral. Ethics.

1 Universidade Federal da Bahia (UFBA), Instituto de Saúde Coletiva (ISC) Salvador (BA), Brasil. martinmezza@hotmail.com 
A Reforma Sanitária não é um projeto técnico-gerencial, administrativo e técnico-científico; o Projeto da Reforma Sanitária é também o da civilização humana, é um projeto civilizatório, que, para se organizar, precisa ter dentro dele valores que nunca devemos perder, pois o que queremos para a Saúde, queremos para a sociedade brasileira.

Sergio Arouca

\section{Introdução}

A teoria do reconhecimento de Honneth (2003) tem por objetivo renovar a crítica social que possa alavancar os processos de emancipação e justiça social. Mediante a primazia da noção de reconhecimento sobre a de interesse, pretende-se alcançar os conflitos mudos da vida social a partir dos quais desenvolver as lutas sociais que levem ao progresso moral das sociedades. O reconhecimento na vida social moderna está suportado na intersubjetividade e na diferenciação de três padrões normativos ou esferas de reconhecimento (amor, direito e estima). Sua tese é que o impulso motivacional para as lutas sociais surge da extensão e da generalização dos sentimentos de injustiça de sujeitos que viram desrespeitadas e feridas as suas expectativas de reconhecimento e, consequentemente, impedida ou dificultada sua autorrealização e sua inclusão social.

No entanto, quando Axel Honneth apresenta os exemplos históricos probatórios da teoria do reconhecimento, omite qualquer menção aos processos da Reforma Psiquiátrica (RP) acontecidos nos principais países da Europa durante a segunda metade do século XX e no final do mesmo século em boa parte de América. Da mesma forma e de modo geral, o campo da saúde mental fica excluído dos interesses dos pesquisadores que utilizam a teoria do reconhecimento para explorar as diversas lutas e as variadas formas de desrespeito social. Por outro lado, as pessoas vinculadas ao campo da Reforma Sanitária e Psiquiátrica não deixam de advertir sobre o fundamental papel do reconhecimento no novo tratamento da loucura, nem de sentir que a luta travada nesses espaços significou um avanço importantíssimo para nossas sociedades, como o prova nossa epígrafe. Contudo, mesmo assim, até o momento inexiste qualquer tentativa de teorização nessa direção.

Nossa proposta será preencher essa lacuna mediante a articulação da teoria do reconhecimento de Axel Honneth e as elaborações em torno do processo de desinstitucionalização e do campo da saúde mental. Para isso, recorreremos analiticamente à história da Reforma Psiquiátrica Brasileira (RPB), considerando a atual conjuntura sociopolítica do Brasil.

\section{A Reforma Psiquiátrica como luta pelo reconhecimento}

Todos os grandes processos de RP surgidos na segunda metade do século XX (inglês, francês, americano e italiano) questionaram o poder manicomial que se mascarava na objetividade da doença mental. Entretanto, como bem salienta Foucault ${ }^{1}$, as estratégias desses movimentos foram diferentes. Foi a psiquiatria democrática, alicerce ideológico e técnico da $\mathrm{RPB}$, quem mais claramente iluminou e operou sobre as relações de poder presentes no tratamento segregativo do sujeito com doença mental, tanto no interior do manicômio quanto nas relações sociais.

O trabalho de Galende e Kraut ${ }^{2}$ evidencia que, nas formas históricas dos tratamentos psiquiátricos, não existia uma diferença clara entre os meios de castigo e os procedimentos terapêuticos. Os autores afirmam que a maioria dos psiquiatras da metade do século XIX argumentava sobre os benefícios terapêuticos dos castigos corporais. Assim, para o doutor Lichtenberg os golpes de bengalas eram úteis para que o louco recobrisse a relação com a realidade; e o doutor Reil, entre muitos outros, afirmava que a camisa de força, a fome 
e alguma outra privação eram eficazes para tornar dóceis os furiosos.

Um desses tratamentos criados em 1949 teve um reconhecimento social particular. A psicocirurgia, ou mais conhecida como lobotomia, foi honrada com o prêmio Nobel. Não podemos esquecer o eletrochoque, criação contemporânea à psicocirurgia, e o choque insulínico idealizado pelo doutor Manfred Sakel ao trabalhar com toxicomanias. Os princípios que inspiraram todas essas invenções da primeira metade do século XX, mesmo que mascarados e deslocados, assentam-se no modelo asilar da época de Esquirol em que o poder do médico - agora dos tratamentos - tem por finalidade confrontar a paixão pervertida do louco. Nesse modelo, "é preciso aplicar um método perturbador, quebrar o espasmo com o espasmo"3, ou seja, ao provocar estados de comoção psíquica e padecimentos físicos intensos, pretendia-se afetar a centralidade das ideias delirantes.

Nos dias de hoje, ainda pode-se ver como o castigo assombra a bela alma do psiquiatra. $\mathrm{Na}$ Argentina, a categoria médica expressou sua indignação pelo fato da Lei de Saúde Mental ${ }^{4}$ (26.657/2010), no seu art. $n^{0} 12$, dizer que a prescrição de medicamentos só pode ser com fins terapêuticos, e nunca como castigo. Também aqui na Bahia, a imaculada e, sem dúvida, tão objetiva como a histórica e seletiva consciência do doutor Luiz Fernando Pedroso (diretor clínico da clínica Holiste) viu-se constrangida pela realização do Fórum de Direitos Humanos e Saúde Mental, em junho de 2019 em Salvador, alegando a presença de palestrantes não especialistas, portanto sem competência técnica para falarem sobre transtornos mentais, como é o caso de lideranças quilombola e indígena, antropólogos e outros cientistas sociais, teóricos do movimento negro, entre outros que, para um certo segmento da psiquiatria, não representam o pensamento científico e não são autorizados a falar sobre o tema. Tendo em vista que, durante o Fórum, houve muito debate sobre a remanicomialização da sociedade e o retorno de tecnologias médicas consideradas violadoras de direitos humanos, teve que sair a contestar qualquer associação entre tratamento e castigo, defendendo a pureza da ciência psiquiátrica e fazendo um apelo pela importância da internação involuntária e da eletroconvulsoterapia (coluna do jornal 'A Tarde', julho/2019, SSA-BA).

O castigo no tratamento não perturba apenas a boa consciência médica, senão também às intenções de determinados técnicos da RPB, como o demonstra o caloroso debate - do qual tivemos a oportunidade de participar - durante um encontro na Defensoria Pública de Salvador no ano de 2015. Ali, profissionais levantaram a questão das medidas disciplinares existentes nos Centro de Atenção Psicossocial (Caps) como parte do tratamento ou como castigo.

Foi Goffman ${ }^{5}$ uns dos que iluminaram essa realidade nos manicômios dos Estados Unidos da América. $\mathrm{O}$ autor denunciou que as instituições psiquiátricas, que se proclamavam científicas, em realidade faziam parte da grande família das instituições totais, já que compartilhavam com elas a característica de impor uma barreira à relação social e ao vínculo com o mundo externo durante um tempo prolongado. Onde se afirmava a objetividade do tratamento médico, Goffman encontrará a presença maciça da 'carreira moral do doente mental'. Longe de algum tratamento que favoreça uma recuperação, observou-se a perda contínua e progressiva das capacidades sociais.

Quando em 18 de junho de 1979, na conferência proferida no instituto Sedes Sapientiae de São Paulo, Basaglia' ${ }^{\text {(29-31) }}$ conta do que se tratou a experiência de Gorizia e Trieste, ele utiliza coloquialmente o conceito de reconhecimento. Com um enorme poder de síntese diz que o 'descobrimento' da psiquiatria democrática foi 'reconhecer' que o "doente não é apenas um doente, senão um homem com todas as suas necessidades" e em dizer "não à miséria e à prática psiquiátrica "choque insulínico e eletrochoques imperante nos manicômios".

Temos aqui os dois elementos a partir dos quais desenvolveremos nossa argumentação. Basaglia diz que parte de um não, de um não à psiquiatria e de um não à miséria. 
Esse não inicial se transformará no dispositivo de desinstitucionalização. A meta da Reforma Psiquiátrica que ele defende passa a ser a destruição dos manicômios por serem o suporte material a partir do qual se contradiz o princípio da liberdade, se mantém o sistema de desigualdades sociais e se reproduzem a violência e a marginalização. O que fica questionado é a função social de controle da disciplina psiquiátrica.

Esse dispositivo será novamente repensado quando, mediante a noção de 'reviravolta', tente-se captar o ato permanente de desinstitucionalização. $\mathrm{O}$ alvo passa a ser as várias e cotidianas formas de opressão, controle e segregação, incluída a 'violência técnica' (Crimini de Pace) empreendida agora pelos técnicos da 'nova psiquiatria' e os especialistas das 'equipes multidiciplinares' ${ }^{7}$. O que fica questionado aqui é a nova tendência a controlar os conflitos sociais por meio da razão técnica.

É realmente simples perceber que, na base do processo de desinstitucionalização, encontram-se 'sentimentos coletivos de injustiça', ou seja, uma reviravolta contra as condições intersubjetivas que determinam as formas de reconhecimento manicomial. A revolta é contra as experiências morais de desrespeito manicomial que alcançam as três esferas de reconhecimento (amor/violação, direito/ privação e solidariedade/exclusão) e que se expressam da seguinte forma: os maus-tratos e violação são as práticas que negam o amor como padrão de reconhecimento e produzem feridas profundas e douradoras na confiança em si mesmo e no mundo (morte psíquica). A noção de 'humilhação do eu' de Goffman é muito próxima dessa concepção.

O que há de se destacar sempre é que a violência não se limita apenas aos excessos dos comportamentos decorrentes da realidade manicomial, senão aos próprios dispositivos de cuidado, como indicados pelos relatos dos usuários e recolhidos pela literatura científica. Na privação de direitos, tem que se contemplar que o padrão de reconhecimento jurídico varia social e historicamente em função da universalização da pessoa moral. A partir desse critério moral operacionaliza-se a exclusão da posse de determinados direitos (morte social) para alguns sujeitos. Basaglia denuncia a participação das ideias de periculosidade e irrecuperabilidade das pessoas com transtornos psíquicos na produção da desigualdade moral e na exclusão da maioria dos direitos, alcançando seu ápice na interdição ou tutela (morte civil). Já na degradação e ofensa, observa-se a depreciação de algumas formas de vida a partir da negação de estima aos valores de autorrealização associados a ela, que leva a uma diminuição da autoestima pessoal (vexação). Basaglia identifica muito rapidamente como o manicômio opera essa ofensa sobre o nexo entre a classe trabalhadora e a loucura, quando diz que o dispositivo manicomial acolhe aos 'loucos pobres'.

Essa sensibilidade para com as experiências morais de desrespeito manicomial compõe a base motivacional da psiquiatria democrática italiana. Foram esses sentimentos e não os interesses contrapostos, enquanto categoria racional que expressa a tensão pela distribuição desigual objetivada de oportunidades materiais de vida, os que criaram as condições para o protesto, a reviravolta e a resistência promovidas pela psiquiatria democrática.

Vemos como a RP compartilha com as lutas sociais pelo reconhecimento de uma base motivacional. Contudo, resta considerar se a sua fenomenologia segue os alinhamentos gerais estabelecidos para outros subgrupos da vida social, sobretudo no que diz respeito ao nexo entre as vivências privadas de lesão e as formas de reconhecimento exigidas a partir de uma luta social. Para abordar essas questões, colocamos como pano de fundo duas hipotéticas objeções que poderiam levantar-se contra nossa tese: a) a dificuldade para ampliar as experiências morais de desrespeito de sujeitos em sofrimento psíquico e assim motivar o surgimento de movimentos e lutas sociais, associada à condição do 'mínimo de autonomia' de nossos sujeitos para participar da esfera pública; e b) como consequência 
disso, no campo da saúde mental, o sujeito das experiências morais de desrespeito é um (o louco) e o sujeito do movimento e da luta social é outro (os profissionais de saúde).

Formulemos corretamente as perguntas: como se produz o nexo entre as experiências individuais de desrespeito e os sentimentos coletivos de injustiça no contexto da psiquiatria democrática? Como se tornou uma luta social o processo de desinstitucionalização? A desinstitucionalização segue a fenomenologia das experiências de injustiça social consagrada para outros subgrupos?

Quando Honneth ${ }^{8,9}$ se afasta da dimensão normativa e passa ao campo empírico para justificar a teoria do reconhecimento, recorre, principalmente, aos trabalhos sobre os conflitos obreiros em E. P. Thompson e de B. Moore. Nessa perspectiva, articulará as lutas sociais como efeito de inovações políticas ou econômicas que causariam uma infração do 'consenso normativo tácito' ou 'contrato social implícito', ferindo assim a identidade herdada desse. Assim, sugere-se a ideia de uma identidade primeira, estável e uniformizada nos consensos, uma inovação segunda e desestabilizadora deles, para terminar em um terceiro tempo no qual os sentimentos de injustiça causariam uma resistência com uma tonalidade excessivamente ou reparadora ou conservadora da identidade prévia.

Não queremos dizer que as elaborações de Honneth sobre o núcleo normativo das experiências de injustiça social se reduzam a essa lógica, nem descartamos que essa seja a fenomenologia dos grupos estudados pelos autores. Apenas queremos salientar que existe a possibilidade de se aferrar excessivamente à fenomenologia desse referente empírico, sobretudo quando a teoria do reconhecimento carece de uma quantidade suficiente de pesquisas empíricas sobre subgrupos sociais. Dessa forma, corre-se o risco de reduzir ou limitar a normatividade do aspecto motivacional das experiências de injustiça. Enfim, aplicamos à teoria do reconhecimento o mesmo senso crítico que Honneth propõe para o marxismo e para a teoria da redistribuição de Nancy Fraser, ou seja, fazer depender excessivamente sua teorização de um referente empírico privilegiado do descontentamento social - neste caso, seria aplicado à fenomenologia motivacional dos sentimentos de injustiça. O proletariado, no caso do marxismo, e os novos movimentos sociais das políticas de identidade em Fraser, e os movimentos obreiros para Honneth.

Propomos que, para o campo da saúde mental, o "mal-estar da inadequação"10(269) das consciências da loucura funciona como "consenso normativo tácito". Referimo-nos ao descompasso identificado por Foucault entre as experiências de exclusão e proteção e a sua experiência teórica. A separação de duas morais sobre a loucura na época clássica; mas, também, à aspiração de unidade que a psiquiatria moderna pretende mediante $o$ desenvolvimento da consciência analítica que, por supor ocultar seus vínculos com a desrazão, não vai além do "patetismo da doença mental".

Assim, tanto as inovações quanto o aprofundamento dos hábitos intersubjetivos que funcionam como alicerce das formas de reconhecimento podem produzir as feridas na identidade-moral que dão passagem aos sentimentos de injustiça que embasam a luta antimanicomial. O mal-estar inarticulado da inadequação das consciências ora é tocado pelas inovações ora pelos aprofundamentos.

A negação de um sistema é resultante de uma reviravolta, da produção de uma crise no campo no qual atuamos [...] sistema psiquiátrico, como sistema científico e ao mesmo tempo institucional [...] isto significa que em contato com a realidade institucional têm-se evidenciado elementos - em nítida contradição com as teorias científicas - que remetem a mecanismos estranhos à doença e ao respectivo tratamento. Isto não pode deixar de pôr em crise as teorias científicas sobre o conceito de doença, bem como as instituições sobre as quais elas baseiam as aç̃̃es terapêuticas"1(96-97).

Aqui temos articulada a reviravolta (sentimentos de injustiça) à crise de nosso campo, mas isso será abordado depois. Primeiro, queremos 
salientar que o processo de desinstitucionalização não surge como efeito de uma inovação, senão de um aprofundamento das tensões implícitas no consenso normativo tácito exprimido no sistema científico-institucional da psiquiatria. $O$ germe da reviravolta da desinstitucionalização não é uma inovação, e sim o desenvolvimento da consciência analítica - teoria científica da doença mental - cujo efeito é o aprofundamento das tensões já existentes na inadequação estrutural das consciências da loucura (fundo mascarado de desrazão). Isso tem possibilitado que as contradições ganhem a força necessária para questionar o contrato social implícito, ou seja, o mal-estar mais ou menos aceito da inadequação entre a realidade institucional e a teoria científica se tornou insuportável.

O processo de desinstitucionalização mostra que a revolta é menos contra uma inovação que fere uma identidade herdada (consolidada), que sobre uma infração que impede a possibilidade de novas identidades e formas de reconhecimento. Em outras palavras, poderíamos dizer que a crise, a reviravolta que está no cerne da psiquiatria democrática é efeito da promessa incumprida da ciência médica de tornar o louco um ser humano doente - como qualquer outro.

Esse é o mal-estar que denuncia Goffman ${ }^{5}$ ao dizer que, onde se propõe o tratamento médico, ainda impera a 'carreira moral'. Ademais é esse o desrespeito contra o qual se revolta Basaglia ao advertir que, sob o pretexto da doença mental e dos avanços científicos, opera-se uma nova exclusão da parte de baixo da sociedade. Talvez seja a noção de 'duplo da doença mental' 7 a que melhor expresse essa realidade. Sobretudo, é entendida como construção institucional e ideológica que se impõe mediante a negação (não dialética) do sofrimento existencial das pessoas, os processos de subjetivação e as dinâmicas identitárias.

Chegados a este ponto, estamos em ótimas condições para dizer que a crítica que se articula nas objeções que imaginamos (a dificuldade para ampliar as experiências morais de desrespeito, devido aos problemas em torno do mínimo de autonomia e a diferença da participação dos sujeitos nesse processo da reforma), em realidade, é uma oportunidade para devolver à teoria do reconhecimento uma ampliação da normatividade das fontes motivacionais das lutas sociais. Embora seja verdade que Honneth ${ }^{\mathbf{8}, 9}$, quando faz referência às experiências de desrespeito que estão na base das exigências de reconhecimento, inclua a expressão 'psicológicas-morais', não podemos deixar de constatar que sua elaboração sobre a fenomenologia das experiências de injustiça social tende para uma concepção individualista e psicologicista da questão identitária.

Essa tendência, que tem sua raiz no digno interesse de superar o que o autor chama de deficit sociológico, decorrente de um certo uso da noção de social e de um excessivo procedimentalismo, acaba por sugerir que a motivação para as lutas sociais somente nasce da vivência individual de desrespeito de aspectos da personalidade. Ao excluir a participação no complexo motivacional daqueles sujeitos que não experimentam a humilhação no seu próprio ser (personalidade), faz-se lugar a críticas como a de Correa ${ }^{12}$. A autora questiona a validade universal do aspecto motivacional da luta pelo reconhecimento, quando constata situações de humilhação não experimentadas assim pelos próprios sujeitos.

Contudo, vemos que dois sujeitos são excluídos da participação das fontes motivacionais do descontentamento social. Por um lado, todo aquele que não tenha vivenciado na sua pele a humilhação; por outro, aqueles sujeitos que, pela sua posição social desqualificada, não estariam em condições de perceber os desrespeitos dos quais são objeto. Em nosso campo, o primeiro sujeito seriam os profissionais da saúde; e os segundos, os usuários de saúde mental, cuja desqualificação específica estaria vinculada ao não ter alcançado esse 'mínimo de liberdade e autonomia' ou potencial moral para perceber as humilhações e ampliar os sentimentos de injustiça.

Não pretendemos negar a diferença dos sujeitos com padecimento mental. Muito pelo contrário, o que nós dispomos a fazer não é outra coisa que tomá-la pelo avesso: seu 
reconhecimento distorcido. Dessa forma, não questionamos a particularidade de nossos sujeitos, senão as duas concepções que, nas objeções apresentadas, funcionam como hipokeimenon. A primeira refere-se à ideia que entende a loucura como uma monstruosidade. Aqui, a gravidade conferida à loucura (consciência trágica) dissolve as variadas formas e a diversidade de graus que a constituem. Já a segunda, que não podemos deixar de identificar como vinculada a uma filosofia antropológica investida por princípios liberais e atomísticos, produz uma excessiva identificação entre sujeito e ser individual. Dessa forma, os movimentos ou lutas sociais são passados pelo crivo do contrato social de Hobbes, resultando o efeito ou produto da racionalidade de indivíduos isolados que enxergam nos movimentos sociais o melhor meio para seus fins.

Ambas as concepções - a homogeneidade da loucura e a primazia do sujeito singular ou, o que é o mesmo, a identificação do sujeito político com o indivíduo - enfraquecem a descrição do fenômeno ao negligenciar a diversidade e complexidade dele. Quando Goffman ${ }^{\mathbf{1 3}}$ aborda a vida coletiva dos sujeitos estigmatizados, parte da distinção entre categoria e grupo. A categoria engloba a totalidade dos membros e favorece as relações entre eles, assim como a formação do grupo, do qual não necessariamente participam a totalidade dos membros. No entanto, aqueles que participam do grupo foram divididos pela caracterização realizada por Goffman nas figuras dos 'iguais' (nativos) e dos 'informados' (normais). Os iguais são sujeitos que, embora compartilhem o estigma do grupo, têm uma habilidade maior para se expressar ou estabelecer relações com o mundo social que o resto de seus colegas. Já os informados são pessoas que por sua posição social compartilham a vida íntima do estigmatizado e têm uma estima por eles, que fazem com que sejam aceitos pelo grupo.

Essa sucinta descrição é suficiente para provar que os movimentos sociais têm como alicerce uma estrutura intersubjetiva que inclui as tensões entre a homogeneidade e a diversidade. A vida coletiva dos sujeitos estigmatizados, inclusive a de sujeitos em sofrimento psíquico, supõe tanto uma diversidade dos 'iguais' quanto uma interação com os diferentes. Sem prejuízo de desconhecer a particularidade específica dos grupos de estigmatizados, tem que dizer que, nesse ponto, não se diferenciam tanto dos grupos sociais não desacreditados. Por exemplo, se pensamos na estrutura das reivindicações laborais, veremos que também há uma tensão entre os dirigentes sindicais e a base, o que significa claramente que existem sujeitos com maior capacidade que outros para expressar as situações de opressão da categoria.

Acreditamos que o elaborado até aqui exige considerar o desenvolvimento moral dos movimentos sociais menos a partir de uma ilusória homogeneidade ontológica ou em um indeterminado núcleo individual que por meio da estrutura intersubjetiva dos vínculos sociais. Entretanto, se o nosso interesse foi argumentar a favor da inclusão da RP como luta social pelo reconhecimento, ao fazê-lo, também conseguimos aportar subsídios para ampliar a normatividade da noção de reconhecimento, sobretudo no que diz respeito a sua base motivacional.

Afirmamos que o processo de desinstitucionalização não surge apenas dos sentimentos de injustiça decorrentes das humilhações sofridas pelos internos do manicômio. Essas experiências de desrespeito se articulam aos sentimentos de um grupo de profissionais que se revoltam (reviravolta) tanto contra as humilhações sofridas pelo outro (empatia) quanto com a contradição entre a teoria científica e a realidade institucional (inadequação estrutural das consciências da loucura). Essa crise, essa contradição, também deve se entender como um fato que fere o consenso normativo tácito, ou as pretensões articuladas a ele.

Dessa forma, as lutas sociais podem ter como alicerce situações de desrespeito, de revolta, ou uma conjugação de ambas. Em palavras de Iser ${ }^{14}$, o descontentamento social pode surgir de aspectos psicológicos ou normativos, da vulnerabilidade psíquica ou dos deveres recíprocos. 
Enfim, a noção de revolta tem a capacidade de incluir na luta pelo reconhecimento a participação daqueles atores sociais que, não vivenciando individualmente situações de desrespeito, não ficam indiferentes elas.

Embora o apresentado até aqui já responda à dificuldade para ampliar as experiências de desrespeito, pensamos que podemos dizer algo mais ao considerar o deficit de autonomia das pessoas com sofrimento psíquico em relação ao processo de desinstitucionalização. A pergunta de partida poderia ser: tendo em conta esse deficit de autonomia do sujeito com transtorno mental, como fez o processo de desinstitucionalização para ampliar as experiências de desrespeito individuais? Sinteticamente poderíamos responder que essa ampliação veio mediante a introdução dos padrões de reconhecimento do direito, da solidariedade e a criação de uma semântica da liberdade que tinha como objetivo a destruição de todos os mecanismos de reconhecimento do dispositivo manicomial. Outrossim, essa destruição tem como consequência lógica o questionamento do mínimo de autonomia e liberdade da doença mental articulado pela instituição psiquiátrica.

Essa ideia, que já desenvolveremos, está contida na definição que o próprio Basaglia ${ }^{6}$ propõe para explicar a ação da desinstitucionalização como

somente a inserção na normativa sanitária de um elemento civil e constitucional que deveria ter sido implícito [...] um ato de reparação que a democracia realiza com os cidadãos.

Essa inserção do elemento civil e constitucional na normativa sanitária, representada pela interpenetração entre as esferas, não é outra coisa que a intervenção da ação desinstitucionalizadora na base material da relação entre o louco e o poder do médico. A desinstitucionalização abre o reconhecimento do louco aos padrões que a relação manicomial de reconhecimento fecha. É dessa maneira que se produz simultaneamente um efeito terapêutico e social, que resulta, ao mesmo tempo, em uma maior individualização e inclusão social.

Figura 1. Reconhecimento da desinstitucionalização

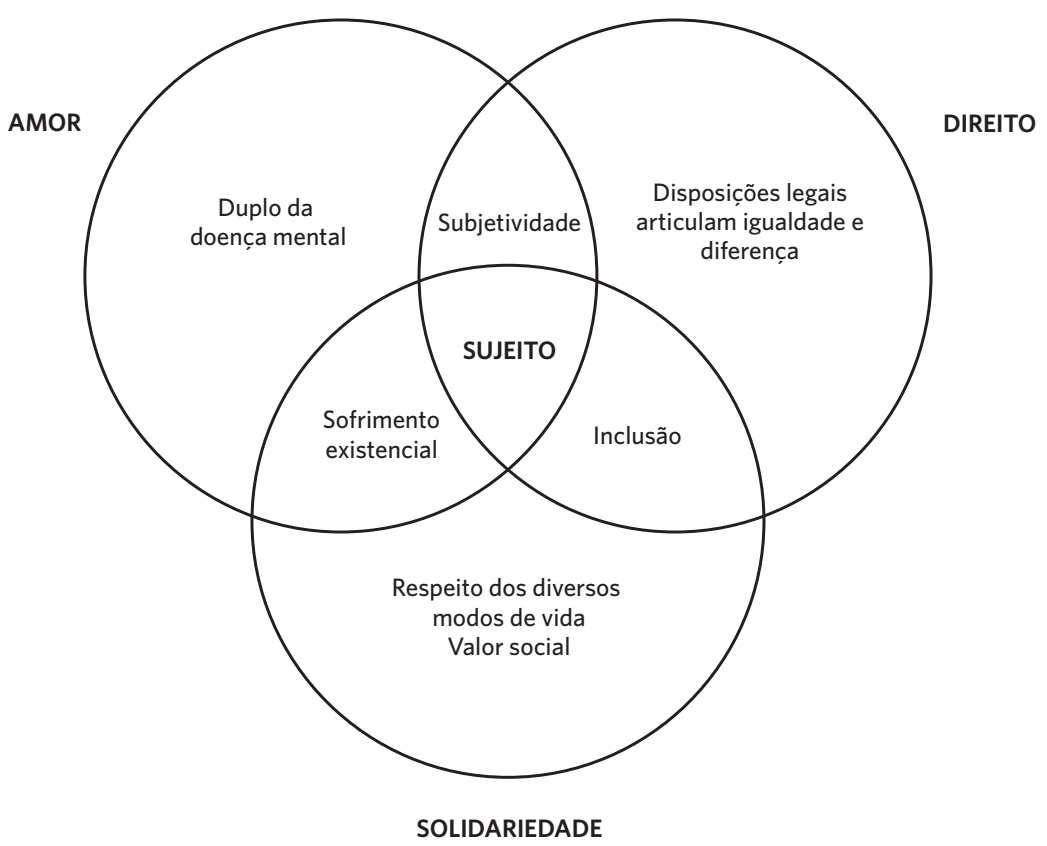


A relação manicomial entre o louco e o médico bem pode ser entendida como uma dobra na esfera do amor. De fato, sempre se tem interpretado a figura do médico como substituto do papel paterno e o manicômio como o lar das pessoas reclusas e abandonadas nele. De alguma forma, as relações próximas com a figura do médico substituíam toda relação social, impondo-se como o mundo natural do louco.

A captura do louco nas relações primárias entre médico e paciente - se produz a partir de uma férrea articulação com as distorções no reconhecimento ocorridas nos padrões do direito e da eticidade. Dessa forma, a periculosidade do louco (esfera do direito) e a irrecuperabilidade, incapacidade ou improdutividade do doente mental (vida pública) funcionam como verdadeiras trancas que colaboram para o isolamento do louco na esfera do amor. O discurso manicomial e o da psiquiatria positiva, mediante o primado da consciência analítica, esquecem sua própria ação - a mão invisível que aciona o ferrolho - sobre esse mínimo de liberdade e autonomia do doente mental e passam a considerar a periculosidade e a incapacidade como um dado natural. Nesse contexto, a exclusão social aparece como lógica e inevitável.

Figura 2. Reconhecimento manicomial

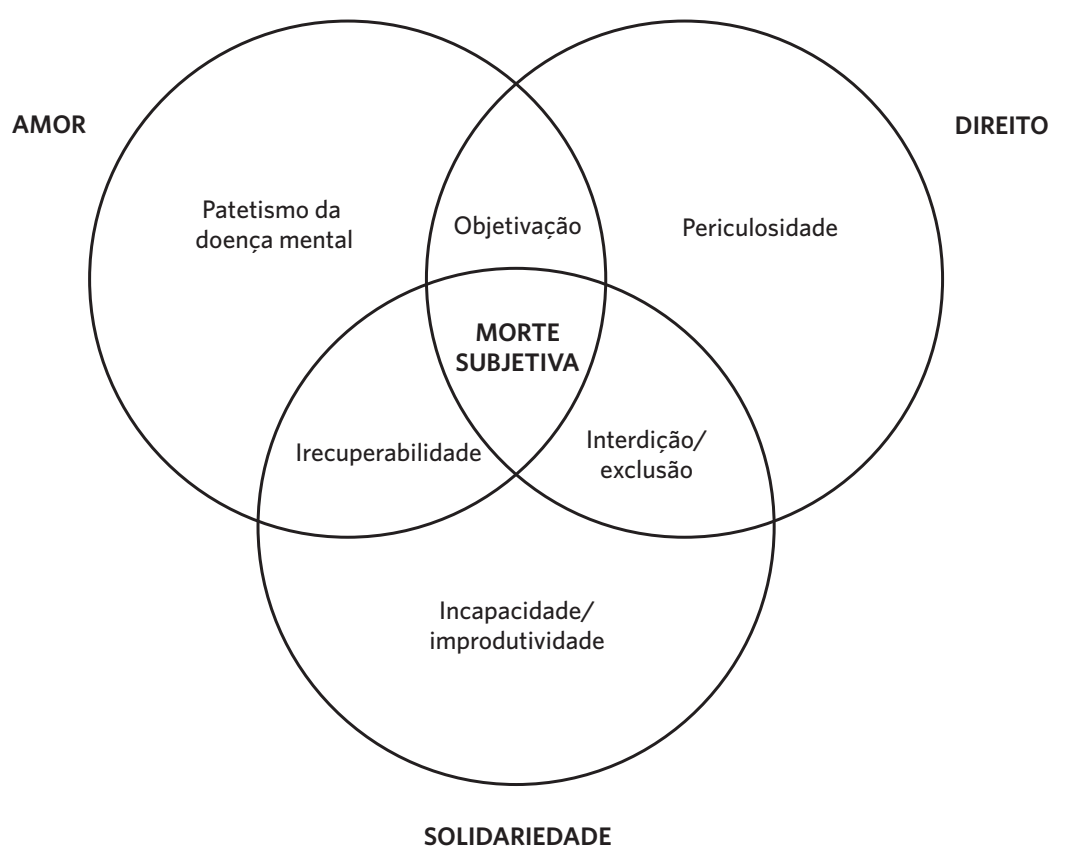

No entanto, onde a consciência analítica se fecha sobre si mesma e pretende falar da única realidade objetiva e natural da doença mental, a desinstitucionalização introduz a noção de duplo da doença mental. Com ela, denuncia-se a patologia psiquiátrica como construção institucional que captura o sofrimento das pessoas a partir da negação (não dialética) das subjetividades e das identidades. A proposta de Basaglia será colocar a doença mental entre parênteses, suspendê-la, para, dessa forma, lidar com as consequências institucionais e permitir direcionar a atenção e os cuidados aos aspectos pessoais, subjetivos e sociais ${ }^{\mathbf{1 5}}$. 
Colocar a doença entre parênteses não é negar sua existência nem afirmar que não exista algo que produza dor, sofrimento ou mal-estar. A doença entre parênteses opera a ruptura com os aspectos epistemológicos, científicos, legislativos, administrativos e culturais, assim como com as relações de poder estruturadas em torno da doença mental. O que se nega é a elaboração teórico-prática (institucional e ideológica) que a psiquiatria faz do fenômeno da loucura e da experiência de sofrimento psíquico. Seria algo assim como uma negação da negação, ou seja, nega-se a negação operada pela psiquiatria: 0 "imperativo a aderir a uma doença abstrata, simbólica e, enquanto tal, ideológica"16(309).

A negação operada sobre o 'patetismo da doença mental'17 abre caminhos para novas gramáticas de reconhecimento da existência e do sofrimento psíquico, que entram em conflito com a reprodução da imagem da loucura operada pela instituição psiquiátrica. Enfim, o que estamos dizendo é que a negação da instituição psiquiátrica, com a noção de duplo da doença mental, questiona o potencial moral da loucura, esse mínimo de liberdade e autonomia do doente mental estabelecido pela lógica manicomial e pela psiquiatria positiva. Contudo, não hesitamos em esclarecer novamente que não se trata de negar que o sofrimento psíquico restrinja, em alguma medida, a liberdade e a autonomia do sujeito. Apenas denuncia-se que, sob essa limitação, monta-se uma lógica institucional que acrescenta o sofrimento e restringe ainda mais a liberdade - tal como é exprimido pela noção de carreira moral.

Dessa forma, a ação desinstitucionalizante pode ser entendida como aquela que transcende o contrato terapêutico (interações primárias da esfera do amor), as humilhações que se produzem nele, para melhor compreendê-las na sua articulação com as formas de desrespeito dos padrões de reconhecimento da esfera do direito e da eticidade - e é sobre esse nó de desrespeito, constituído pelos três padrões de reconhecimento, que opera o discurso da liberdade articulado pela psiquiatria democrática. Por isso, por atuar nesse liame é que esse discurso funciona como uma ponte semântica capaz de ampliar as experiências privadas de respeito dos sujeitos, enquanto alcança tanto a figura do doente quanto a do profissional de saúde (deixa de ser - se libera - um agente da opressão do controle social e se torna um porta-voz - normal informado - dos sujeitos em sofrimento psíquico), assim como articula a igualdade e diferença com outras figuras da parte de baixo da vida social.

\section{A Reforma Psiquiátrica como progresso moral da sociedade}

Até aqui argumentamos a favor da desinstitucionalização como luta pelo reconhecimento. Resta-nos a tarefa de provar seu vínculo com o progresso moral da sociedade. Para tal fim, bastará um breve percurso histórico pela RPB e a consideração da nossa triste atualidade. $\mathrm{Na}$ década de 1970, em um franco descompasso com as tendências antimanicomiais dominantes no mundo, no Brasil, em um contexto social e político marcado pela ditadura militar, foram construídos vários manicômios, especialmente nas regiões Sudeste e Nordeste ${ }^{18}$. Dessa forma, a população internada passou de 14 mil para 98 mil (1982), situação marcada pelos desvios de dinheiro público para o âmbito privado ${ }^{19}$.

Nesse contexto e como parte do processo de democratização impulsionado em grande medida pela Reforma Sanitária (RS) e pela RPB, desenvolveram-se as premissas e os projetos inscritos no ideário antimanicomial. Época de grande efervescência na qual a participação de personalidades internacionais como Franco Basaglia, Michel Foucault, Ronald Laing, Felix Guattari e Robert Castel deixaram uma marca indelével em toda uma geração de brasilei$\operatorname{ros}^{20}$. Assim, em 1979, na sua estadia no Brasil e durante uma coletiva de imprensa, Franco Basaglia6(139) disse: "Estive hoje num campo de concentração nazista. Em lugar nenhum do mundo, presenciei uma tragédia como essa". 
Estava referindo-se ao maior hospício do Brasil, popularmente conhecido como Colônia, localizado na cidade de Barbacena. A principal referência internacional da luta antimanicomial, investida com uma elevada autoridade e um íntimo conhecimento das diversas realidades manicomiais de grande parte do mundo, no final do século XX e há apenas 41 anos do momento atual, chamou uma instituição da sociedade brasileira como um campo de concentração e a pior tragédia que ele já havia observado. Diagnóstico social e político suficientemente preciso e próximo no tempo, que exige a sua incorporação em qualquer análise atual do processo da RPB.

Alguns fatos revelados pelo livro 'Holocausto brasileiro'21 nos auxiliam na compreensão de realidade descrita por Basaglia. Pelo menos 60 mil pessoas morreram no Colônia; em determinados períodos, houve 16 óbitos por dia; inúmeros cadáveres foram vendidos às faculdades; no mínimo 30 bebês foram roubados das mães; os eletrochoques causavam a interrupção da rede elétrica da cidade; cerca de $70 \%$ dos internos não tinham diagnóstico de doença mental: eram prostitutas, homossexuais, epilépticos, alcoólatras e outras figuras da marginalidade social.

Essa gritante realidade de desrespeito aos direitos e às mínimas condições de dignidade humana tem como ponto de virada o marco institucional constituído pelo II Encontro Nacional de Trabalhadores de Saúde Mental, no qual se opta pela eliminação dos manicômios e das práticas manicomiais. Em 1989, o deputado Paulo Delgado (PT-MG) apresentou o Projeto de Lei $n^{\circ} 3.657 / 89$ que, depois de muitas negociações e disputas políticas, conseguiu sua aprovação final em abril de 2001, mediante a Lei Federal no $10.216 / 2001^{22}$. Daí em diante houve uma sucessão complexa e sistemática de leis estaduais e municipais, assim como portarias ministeriais que acabaram por constituir um arcabouço normativo importante ${ }^{23}$ para a construção de serviços substitutivos de base comunitária e territorial ${ }^{24}$.

Os avanços na construção e expansão da rede de serviços substitutivos constituem uma evidência inegável, como fica demonstrado por uma série de relatórios e estudos produzidos no próprio campo da saúde mental ${ }^{23-26}$. Essas informações sobre a Rede de Atenção Psicossocial (Raps) confirmam os avanços da RPB em termos de construção de cuidados extra-hospitalares e de ampliação de cidadania, exprimidos em uma série de ações e tecnologias: Caps, serviços ambulatórios de referência, residências terapêuticas, leitos em Hospitais Gerais, pontos de encontro, centros de convivência, oficinas de geração de renda e trabalho, ações intersetoriais de inclusão social no trabalho e nas outras áreas civis, consultórios de rua, integração da rede à Estratégia Saúde da Família (ESF), matriciamento da saúde mental por meio dos Núcleos de Apoio à Saúde da Família, programas de reabilitação de 'volta pra casa', trabalho protegido 'Programa geração de renda', lazer assistido etc.

Toda essa rede, além de conotar a mudança do paradigma da doença mental para o da saúde mental ${ }^{27}$, representa o suporte material por onde se instrumentaliza a ampliação do reconhecimento da pessoa com sofrimento psíquico. O cuidado que a Raps promove tem como alicerce valores morais que procuram favorecer o maior grau de 'autorrealização' das pessoas com sofrimento psíquico (reconhecimento das pretensões da personalidade e ampliação da liberdade individual), assim como sua inclusão nos padrões de igualdade social. Dessa forma, não somente se busca incluir os brasileiros com transtorno mental no campo da saúde pública (igualdade), mas também se procura a aceitação social da sua diferença específica nas relações sociais de solidariedade. Enfim, a luta pelo reconhecimento impulsionada pela RPB cria as condições para a autorrealização e, dessa maneira, produz uma ampliação da civilidade que resulta no progresso moral da sociedade.

Mesmo destacando essas conquistas, a literatura de referência nunca deixou de apontar para o que chamou alternativamente de desafios ou impasses, podendo ser resumidos 
na burocratização, desigualdade regional e subfinanciamento. Essa realidade que, sem dúvida, também compreende falhas e limitações próprias, em grande medida se explica pela ação contínua de uma variedade de atores com ideologia e interesses contrários à RPB que articulam o processo sociopolítico e cultural nomeado como contrarreforma. A força e legitimidade que tem ganhado nos últimos anos em função das transformações políticas no Brasil (giro liberal, autoritário e fascista), evidenciam sua participação permanente mais silenciosa - nos impasses da RP.

Talvez tenha sido Vasconcelos ${ }^{28}$ uns dos primeiros a diagnosticar o risco dessa virada no Brasil ao identificar as articulações entre políticas conservadoras e políticas neoliberais após as eleições de 2010. Risco também apontado e contextualizado por Desviat quando, em 2014, na Conferência no Instituto de Saúde Coletiva de SSA-BA, indicou que as recentes mudanças políticas, sociais e econômicas na Europa, depois de muitos anos, trouxeram uma nova tendência a favor da manicomialização.

Foi em 2015 que vimos essas forças atuarem à luz do dia. Em dezembro desse ano, o Ministro de Saúde doutor Marcelo Castro em um contexto político no qual a presidente Dilma Rousseff começava a ceder para evitar o lamentável golpe institucional de 2016 - anunciava a substituição do coordenador de Saúde Mental e referente da Reforma Psiquiátrica, o Dr. Roberto Tikanori Kinoshita, pelo Dr. Valencius Wurch Duarte Filho, cuja trajetória profissional está ligada às experiências manicomiais. Após esse ato institucional e simbólico, a Coordenação Nacional de Saúde Mental, com apoio da Associação Brasileira de Psiquiatria (ABP), implementou uma "reversão da política antimanicomial" mediante o que se deu em chamar de "nova política de Saúde Mental"29(11).

Segundo recentes estudos ${ }^{30-32}$, entre os efeitos dessa nova investida da contrarreforma contam-se: a defesa da eletroconvulsoterapia (ECT); a inclusão do hospital psiquiátrico na Raps e o ajuste do valor da Autorização de Internamento Hospitalar (AIH), com o consequente redirecionamentos dos recursos financeiros dos serviços comunitários para o hospital psiquiátrico; o desenvolvimento de uma política de drogas baseada na abstinência e nas internações nas comunidades terapêuticas; ambulatórios especializados para quadros menos graves em detrimento do matriciamento das equipes da saúde da família; privatização dos serviços e reanimação do modelo biomédico. Destarte, mediante uma série de portarias e alianças com setores estratégicos da cena política e civil, as forças da contrarreforma já não apenas retardam o processo de desinstitucionalização como o fazem recuar.

Recentemente, em uma mesa de debate em Salvador (BA), Arbex ${ }^{33}$ aportou uma nova prova do vínculo entre a degradação moral e os retrocessos da RPB ao comentar um trabalho jornalístico que conseguiu identificar o engavetamento por parte dos governos de Temer e Bolsonaro de uma pesquisa da Fiocruz ${ }^{\mathbf{3 4}}$ sobre o uso de drogas. Essa pesquisa, que não menosprezava de forma nenhuma o impacto social do consumo de crack, indicava um consumo aquém do que a mídia introduz no imaginário social. Arbex afirmou que os governos mencionados autorizaram o repasse de uma quantidade de dinheiro para as comunidades terapêuticas bem superior ao necessário, segundo os dados da pesquisa engavetada.

Considerar tanto os progressos quanto os retrocessos nos permite ver com maior clareza o vínculo entre a RPB e a ordem moral da sociedade. Inclusive, nos permite colocar a RPB como uns dos critérios normativos da direção evolutiva da sociedade brasileira; mas ainda nos faz lembrar que esses critérios normativos estão em disputa e tensionamento permanente.

\section{Considerações finais}

Acreditamos ter argumentado suficientemente de que o processo de desinstitucionalização e a RPB podem entender-se como luta pelo 
reconhecimento e progresso moral da sociedade. Dessa forma, acrescentamos material empírico à teoria do reconhecimento e, ao mesmo tempo, aportamos uma ampliação da sua normatividade, sobretudo, do aspecto motivacional das lutas sociais. O processo de desinstitucionalização, assim como foi analisado por nós mediante as noções de reviravolta, da intersubjetividade dos grupos (as tensões entre a diversidade e homogeneidade exprimida nos iguais nativos e informados) e do trabalho sobre o mínimo de liberdade e autonomia, por meio da negação do dispositivo manicomial e o duplo da doença mental, traz um aporte substancial à dialética entre as feridas da identidade e os sentimentos coletivos de injustiça. Entendemos que toda essa elaboração narrativa tem a virtude de potencializar o discurso e a semântica articulados pela RPB, ao mesmo tempo que brinda subsídios teóricos para repensar as estratégias necessárias para superar os impasses e enfrentar os embates contrarreformistas.

\section{Colaboradores}

Mezza M (0000-0002-0442-4391)* contribuiu para a concepção, o planejamento, a análise e a interpretação dos dados; revisão crítica do conteúdo; e aprovação da versão final do manuscrito. Torrenté MON (0000-0002-59054199)* contribuiu para a revisão crítica do conteúdo e a aprovação da versão final.

\section{Referências}

1. Foucault M. La vida de los hombres infames. La Plata: Editorial Altamira; 1996.

2. Galende E, Kraut AJ. El sufrimiento mental. El poder, la Ley y los derechos. Buenos Aires: Lugar Editorial; 2006.

3. ta: Editorial Altamira; 1996. [acesso em 2020 out 17]. Disponível em: http://23118.psi.uba.ar/academica/ carrerasdegrado/musicoterapia/informacion_adicional/311_escuelas_psicologicas/docs/Foucaullt_ Michel_-_La_vida_de_los_hombres_infames.pdf.
4. Argentina. Ministerio de Justicia y Derechos Humanos. Ley 26.257, 02 de diciembre de 2010. Derecho a la protección de la Salud Mental. Boletín Oficia 02 Dic 2010.

5. Goffman E. Manicômios, prisões e conventos. São Paulo: Perspectiva; 1961.386 p.

6. Basaglia F. La condena de ser loco y pobre. Alternativas al manicomio. Buenos Aires: Topía Editorial; 2008. [acesso em 2020 out 17]. Disponível em: http://www. bibliopsi.org/docs/carreras/musicoterapia/(316)\%20 MUSICOTERAPIA\%20EN\%20SALUD\%20MEN-
*Orcid (Open Researcher and Contributor ID). 
TAL/La $\% 20$ condena\%20de\%20ser\%20loco $\% 20$ y\%20pobre.pdf.

7. Basaglia F. Escritos selecionados em Saúde Mental e Reforma Psiquiátrica In: Amarante P, organizador. Rio de janeiro: Garamond; 2005.

8. Honneth A. Luta por reconhecimento: a gramática moral dos conflitos sociais. São Paulo: Editora 34; 2003. $291 \mathrm{p}$

9. Honneth A. Redistribución como reconocimiento. Respuesta a Nancy Fraser. In: Fraser N, Honneth A. ¿Redistribución o reconocimiento? Madrid: Ediciones Morata, S. L; 2006. p. 89-148.

10. Foucault M. Historia de la locura en la época clásica. Buenos Aires: Fondo de Cultura Económica; 2009.

11. Basaglia F. O circuito do controle: do manicômio à descentralização psiquiátrica. In: Amarante P, organizador. Escritos selecionados em Saúde Mental e Reforma Psiquiátrica. Rio de janeiro: Garamond; 2005. p. 96-97.

12. Correa A. Entre o homem de bem e comum: Um estudo sobre o substrato motivacional para as lutas por reconhecimento em associados de empreendimentos econômicos solidários. [dissertação]. Porto Alegre: Universidade Federal do Rio Grande do Sul; 2012. $150 \mathrm{p}$.

13. Goffman E. Estigma: notas sobre a manipulação da identidade deteriorada. Rio de Janeiro: LTC; 2017.

14. Iser M. Desrespeito e revolta. Sociologias. [internet] 2013 [acesso em 2019 jun 23]; 15(1):82-119. Disponível em: https://seer.ufrgs.br/sociologias/article/ view/42433.

15. Amarante P. O pensamento crítico de Franco Basaglia sobre a ciência e a psiquiatria. In: Amarante $\mathrm{P}$, organizador. Teoria e crítica em saúde mental: Textos selecionados. São Paulo: Zagodoni; 2015. p. 127-148.

16. Basaglia F. Potere ed istituzionalizzazione. Dalla vita istituzionale alla vita di comunità. In: Basaglia FO. (A cura di). Franco Basaglia. Scritti I (1953-1968). Dalla psichiatria fenomenologica all'esperienza di Gorizia. Torino: Einaudi, 1981e. p. 283- 293.

17. Foucault M. Historia de la locura en la época clásica. Buenos Aires: Fondo de Cultura Económica; 2009.

18. Mari J, Thornicroft G. A luta antimanicomial e a psiquiatria. [internet]. A Folha de São Paulo. 2010 maio 18 [acesso em 2019 jun 15]. Disponível em: https://wwwl. folha.uol.com.br/fsp/opiniao/fz1805201008.htm.

19. Alves DS. O “ex" tentando ver o futuro. Cad. IPUB. 1999; 14(21):21-30.

20. Amarante P. Loucos pela vida: a trajetória da reforma psiquiátrica no Brasil. 2. ed. Rio de Janeiro: Fiocruz; 1998. 136 p.

21. Arbex D. Holocausto Brasileiro. São Paulo: Geração Editorial; 2014. 256 p.

22. Brasil. Lei $\mathrm{n}^{0} 10.216$, de 6 de abril de 2001. Dispõe a proteção e os direitos das pessoas portadoras de transtornos mentais e redireciona o modelo assistencial em saúde mental. Diário Oficial da União. 7 Abr 2001. [acesso em 2020 set 25]. Disponível em: http://www. planalto.gov.br/ccivil_03/leis/leis_2001/110216.htm.

23. Pitta A. Um balanço da reforma psiquiátrica brasileira: instituições, atores e políticas. Ciênc. Saúde Colet. [internet]. 2011 [acesso em 2019 nov 13]; 16(12):45794589. Disponível em: http://www.scielo.br/scielo. php?pid=S1413-81232011001300002\&script=sci abstract\&tlng=pt.

24. Berlinck M. O método clínico: fundamento da psicopatologia. Rev. latinoam. psicopatol. fundam. [internet]. 2009 [acesso em 2019 ago 11]; 12(3):55-72. Disponível em: http://www.scielo.br/scielo.php?script=sci_artt ext\&pid=S1415-47142009000300001.

25. Brasil. Ministério da Saúde, Secretaria de Atenção à Saúde, Coordenação Geral de Saúde Mental, Álcool e Outras Drogas. Saúde Mental no SUS: Cuidado 
em Liberdade, Defesa de Direitos e Rede de Atenção Psicossocial. Relatório de Gestão 2011-2015. Brasília, DF: Ministério da Saúde; 2016. 143 p.

26. Desviat M. A Reforma Psiquiátrica. Rio de Janeiro: Fiocruz; 2002.

27. Amarante P. Superar el Manicomio: Salud mental y atención psicosocial. Buenos Aires: Topía Editorial; 2009.

28. Vasconcelos EM. Desafios políticos da reforma psiquiátrica brasileira. São Paulo: Hucitec; 2010.

29. Pitta A, Guljor AP. A violência da contrarreforma psiquiátrica no Brasil: um ataque à democracia em tempos de luta pelos direitos humanos e justiça social. Cad. CEAS. [internet] 2019 [acesso em 2020 jan 4]; 246(1):6-14. Disponível em: https://cadernosdoceas.ucsal.br/index.php/cadernosdoceas/article/ view/525.

30. Lima RC. O avanço da contrarreforma psiquiátrica no Brasil. Physis. 2019; 29(1):1-5.

31. Onoko-Campos RT. Saúde Mental no Brasil: avanços, retrocessos e desafios. Cad. Saúde Pública. 2019; 35(11):1-5.
32. Nunes M, Mendes J, Portugal C, et al. Reforma e contrarreforma psiquiátrica: análise de uma crise sociopolítica e sanitária a nível nacional e regional. Ciênc. Saúde Colet. 2019 [acesso em 2020 jan 5]; 24(12):4489-4498. Disponível em: http:// www.scielo.br/scielo.php?script=sci_arttext\&pid $=$ S1413-81232019001204489.

33. Arbex D. Holocausto Brasileiro. [mesa de debate "Diagnóstico moral: o manicômio em afroperspectiva”. Teatro Goethe-Institut; 2019 out 19; Salvador, Brasil].

34. Bastos FIPM, Vasconcellos MTLB, Reis RB, et al., organizadores. III Levantamento Nacional sobre o uso de drogas pela população brasileira. Rio de Janeiro: Fiocruz; 2017.

Recebido em 27/02/2020

Aprovado em 25/08/2020

Conflito de interesses: inexistente

Suporte financeiro: Conselho Nacional de Desenvolvimento

Científico e Tecnológico (CNPq) 